\title{
A Biotechnological Approach for the Production of Red Gerbera
}

\section{(Gerbera Jamesonii Bolus)}

\author{
Motiur Rahman ${ }^{1}$, Bulbul Ahmed ${ }^{1,2}$, Rafiul Islam ${ }^{1}$, Abul Mandal ${ }^{3}$, Monzur Hossain ${ }^{1}$ \\ ${ }^{1}$ Plant Breeding \& Gene Engineering Lab., Dept. of Botany, Rajshahi University, Bangladesh. \\ ${ }^{2}$ Dept. of Chemistry, Biochemistry \& Physics, University of Quebec at Trois-Rivieres, Quebec, Canada. \\ ${ }^{3}$ School of Life Science, University of Skövde, Sweden. \\ Corresponding author: Bulbul Ahmed. Plant Breeding \& Gene Engineering Lab., Dept. of Botany, Rajshahi University, Bangladesh. \\ E-mail: bulbul.bd09@gmail.com
}

Received 15 Dec 2013; Revised 10 Jan 2014; Accepted 15 Jan 2014

\begin{abstract}
An in vitro propagation of a red Gerbera (Gerbera jamesonii) variety was achieved by culturing flower bud, leaf segments and flower stalk segments of 80 days old field grown plants on Murashige and Skoog (MS) medium supplemented with different concentration (1.0-6.0 mg/l) of 6-benzyl adenine (BA) in combination with single concentration (1.0 mg/l) of $\alpha$-naphthalene acetic acid (NAA). Lower concentration of BA (1.0 and $2.0 \mathrm{mg} / \mathrm{l})$ with NAA induced the explants to form callus. On the other hand when the explants were cultured in higher concentration $(5.0 \mathrm{mg} / \mathrm{l})$ of BA produced shoots and $5.0 \mathrm{mg} / \mathrm{l} \mathrm{BA}$ with $1.0 \mathrm{mg} / \mathrm{l} \mathrm{NAA}$ was found to be the best for shoot proliferation of the three explants optimum response was obtained from flower buds. Further multiplication of shoots occurred upon transfer of shoot clumps to BA containing MS medium. Regenerated shoots were rooted in MS medium with indole-3acetic acid (IAA) or indole-3-buteric acid (IBA) and maximum frequency (81\%) of rooting with highest number (4) of roots per shoot was achieved in MS medium fortified with $0.3 \mathrm{mg} / \mathrm{l}$ IBA. The rooted shoots were acclimatized and successfully established in soil under natural environment with maximum $84 \%$ survivability.
\end{abstract}

Key Words: Gerbera, herbaceous flower, micro propagation, red variety, regeneration

\section{Introduction}


Gerbera flower is very fashionable and widely used as a decorative garden plant or cut flowers [1]. Gerbera is a perennial and herbaceous flowering plant producing different colors of flower. It belongs to the Asteraceae family. The genus Gerbera consists of approximately forty species and out of them, only G. jamesonii is under cultivation. Though it is native to South America, Africa and tropical Asiatic regions, it is cultivated throughout the world in a wide range of climatic conditions. Plants are tender herbs with a height up to 18 to 24 inch and 4 to 10 inch in diameter of flowers. It is also used as a model plant in studying flower formation, commonly known as African daisy which produces very attractive flowers. It has massive demand in the floral industry as cut flower as well as potted plant due to its beauty and long vase life which ranked at fifth among the top ten cut flowers in the world [2]. It has high market value in the western countries, Malaysia, Indonesia, and India; also it has become a popular ornamental plant in Bangladesh and demand of this flower is ever-increasing particularly in urban areas. Though Bangladesh has a favorable climatic condition for Gerbera of international standard (http://www.mdgbangla.org), the supply of Gerbera plantlets is not adequate to fulfill the local demand. Gerbera can be propagated by both sexual and asexual methods. Seed propagation is not always sufficient since impurity of strain produces a great deal of variation [3]. Also, this method is too slow for commercial purposes [4]. Gerbera is mainly supplied to all over Bangladesh from of the commercially cultivating nurseries at Gathkhali in Jessore. They cultivate this plant from cutting imported from India. Micropropagation is the most successful procedure for rapid and commercial multiplication [5, 6, 7, 8]. Profitable micropropagation has so far been confined to ornamental plants such as, Carnation [9, 10, 11], Geranium [12, 13] and Chrysanthemum [14]. Different explants such as stem, flower receptacle, whole floret, floret-segment, epidermis and shoot tip etc. have been used in Chrysanthemum to regenerate plant $[15,16,17]$. In this esteem, biotechnological approach might be a prospective alternative for mass propagation of Gerbera varieties. Therefore, the present study was undertaken to develop an efficient and reliable micropropagation protocol for commercial exploitation of Gerbera flower in Bangladesh.

\section{Methods}

Flower buds (10-12 days after flowering) with flower stalks and terminal leaves were collected from Gerbera plants grown under field condition in a nursery of Gothkhali, Jhikargacha, Jessore.

The plant materials were washed thoroughly under running tap water and treated with adding a few drops of Tween-20 for 10 to 12 minutes to remove the superficial dust particles as well as fungal and bacterial spores. They were then surface sterilized with $0.1 \%$ mercuric chloride for 6 min followed by rinsing them five times with double distilled water inside the Laminar Air flow chamber. Three kinds of explants like flower buds, flower stalk segments $(0.7-0.8 \mathrm{~cm}$ long) and leaf segments $(0.7-0.8 \mathrm{~cm}$ diameter) were aseptically excised. The flower buds were splitted longitudinally into four parts and each part was used as explant. These three kinds of explants were cultured on MS medium with different concentrations (1.0-6.0 mg/l) of BA along with $1.0 \mathrm{mg} / \mathrm{l} \mathrm{NAA}$ for shoot formation. Multiple shoots developed on the explants were sub cultured after 4 weeks on MS medium with 1.0-5.0 mg/l BA only for further shoot multiplication and growth of shoots. Elongated (2.0-2.5 cm long) shoots were excised and transferred to MS medium with 0.1 to $0.5 \mathrm{mg} / \mathrm{IAA}$ IBA or NAA for adventitious rooting.

All media were gelled with $0.7 \%$ Difco Bactoagar and supplemented with $30 \mathrm{~g} / \mathrm{l}$ sucrose. Media $\mathrm{pH}$ values were adjusted to $5.7 \pm 0.1$ prior autoclaving at $1.1 \mathrm{Kg} \mathrm{cm}-2(1210 \mathrm{C})$ pressure for $15 \mathrm{~min}$. All cultures were maintained in a growth room under $16 \mathrm{~h}$ photoperiod with a light intensity of 60-70 $\mu \mathrm{E} \mathrm{m-2} \mathrm{s-1} \mathrm{provided} \mathrm{by} \mathrm{warm} \mathrm{white} \mathrm{fluorescent} \mathrm{tubes.} \mathrm{There} \mathrm{were} \mathrm{10-15} \mathrm{explants} \mathrm{per} \mathrm{treatment} \mathrm{and} \mathrm{the}$ experiments were repeated twice. The regenerated plants were acclimatized and finally transplanted to soil under natural environment.

\section{Results}

Three kinds of explants viz. flower buds, flower stalk segments and leaf segments were excised and implanted on MS medium fortified with six different concentrations (1.0-6.0 mg/l) of BA with single concentration (1.0 mg/l) of NAA. Morphogenetic changes of all three kinds of explants were appeared within 2 weeks of culture. After passing an initial lag phage, the explants increased in size and with increasing time in culture, the explants either developed adventitious bud primordial or formed callus depending on growth regulator formulations present in the culture media (Table 1). The media with low concentration (1.0-2.0 mg/l) of BA with $1.0 \mathrm{mg} / \mathrm{l}$ NAA favored only callogenesis whereas higher concentration (3.0-6.0 mg/l) of BA favored direct shoot organogenesis.

Regeneration from callus was quite complicated and time consuming, thus more concentration was focused on direct shoot regeneration from the explants. Direct shoot formation occurred at high concentration of BA (3.0-6.0 mg/l) +NAA (1.0mg/l) (Table 1). In the combination of MS+BA $5.0 \mathrm{mg} / \mathrm{l}+\mathrm{NAA} 1.0 \mathrm{mg} / \mathrm{l}$, maximum $66 \%, 49 \%$ and $38 \%$ responsive explants were recorded for flower bud, flower stalk segment and leaf segment explants, respectively (Table 1; Fig. D). Conversely, in higher concentration (MS + BA $6.0 \mathrm{mg} / \mathrm{l}$ + NAA $1.0 \mathrm{mg} / \mathrm{l}$ ), shoot formation percentage was quite low (23\% in flower bud, $26 \%$ in flower stalk segment and $20 \%$ in leaf segment (Table 1). Therefore, MS+BA $5.0 \mathrm{mg} / \mathrm{l}+\mathrm{NAA} 1.0 \mathrm{mg} / \mathrm{l}$ was considered as the best formulation for direct shoot 
formation in Gerbera red variety. This result is very much similar with the previous findings in Gerbera [18] where they have used higher concentration of BA for significant shoot formation in Gerbera.

Table 1. Effects of different concentration and combination of plant growth regulator (PGR) for shoot regeneration of red variety Gerbera.

\begin{tabular}{llll}
\hline $\begin{array}{l}\text { Hormonal supplement }(\mathrm{mg} / \mathrm{l}) \\
\text { BA+NAA }\end{array}$ & Explants & $\begin{array}{l}\% \text { of } \\
\text { explants }\end{array}$ & $\begin{array}{l}\text { Mean no. of shoot } \\
\text { per explant }\end{array}$ \\
\hline & & Only callus & - \\
$1.0+1.0$ & FB & Only callus & - \\
$2.0+1.0$ & 36.66 & $3.16 \pm 0.88$ \\
$3.0+1.0$ & 56.66 & $6.71 \pm 0.67$ \\
$4.0+1.0$ & & 66.66 & $7.50 \pm 0.09$ \\
$5.0+1.0$ & 23.33 & $2.30 \pm 0.23$ \\
$6.0+1.0$ & & \\
\hline & & Only callus & - \\
$1.0+1.0$ & LS & Only callus & - \\
$2.0+1.0$ & & 30.00 & $2.16 \pm 0.68$ \\
$3.0+1.0$ & & 36.66 & $3.50 \pm 0.04$ \\
$4.0+1.0$ & & 38.66 & $4.17 \pm 0.57$ \\
$5.0+1.0$ & & 20.33 & \\
$6.0+1.0$ & & $-10 \pm 0.28$ \\
\hline & & Only callus \\
$2.0+1.0$ & & Only callus & - \\
$3.0+1.0$ & FS & 33.33 & $2.46 \pm 0.88$ \\
$4.0+1.0$ & & 46.66 & $5.17 \pm 0.67$ \\
$5.0+1.0$ & 49.66 & $4.50 \pm 0.09$ \\
$6.0+1.0$ & & 26.66 & $2.30 \pm 0.23$ \\
\hline
\end{tabular}

FB = Flower bud, FS = Flower stalk, LS = Leaf segment

It was visible that when the cultures were kept for long time in MS+BA+NAA, such as after 6 weeks, callus was formed at the basal part of the shoots, therefore after four weeks, shoots regenerated in MS+BA $5.0 \mathrm{mg} / \mathrm{l}+\mathrm{NAA} 1.0 \mathrm{mg} / \mathrm{l}$ were transferred for further multiplication on MS medium fortified with different concentrations (1.0, 2.0, 3.0, 4.0, 5.0 \& $6.0 \mathrm{mg} / \mathrm{l})$ of BA. The highest response (96\%, 90\% and $87 \%$ for flower bud, flower stalk segments and leaf segments, respectively) was achieved on the MS medium supplemented with $2.0 \mathrm{mg} / \mathrm{l} \mathrm{BA}$ with a number of 22, 16 and 13 shoots per explant, and mean length of 4.6, 4.1 and $3.8 \mathrm{~cm}$ for flower bud, flower stalk segment and leaf segment, respectively (Table 2). Furthermore, due to the increase of BA concentration, multiplication rate was reduced. One of the key points has to be noticed that among the three explants used, highest regeneration and multiplication rate was recorded on flower bud explants. For commercial rationale, healthy with fast multiplying methods are always considerable, therefore, in the present study MS+BA $2.0 \mathrm{mg} / \mathrm{l}$ was considered as the ideal concentration for multiple shoot formation for the commercial propagation of Gerbera red variety. This result is very much comparable with the previous findings [19, 20].

In vitro proliferated shoots were then implanted for rooting on MS medium fortified with different concentrations (0.1-0.5 mg/l) of IAA, IBA or NAA (Fig. G). Roots were initiated in all concentrations of IBA and IAA but in all concentrations of NAA, only callus was formed at the basal point (Fig I). In this study, the highest frequency of root formation (81\%), maximum number of roots/shoot (4) and highest root length $(4.9 \mathrm{~cm})$ were achieved on MS medium supplemented with $0.3 \mathrm{mg} / \mathrm{l} \mathrm{IBA}$ (Table 3, Fig. H). It was also reported that IBA as the best hormone for root induction in Gerbera [1]. The root induction was however slow at higher concentration of IBA $(0.4-0.5 \mathrm{mg} / \mathrm{l})$. Afterwards in vitro rooted shoots were transferred for acclimatization. First the plantlets were then taken out from the growth room and the medium attached to the roots was gently washed out with running tap water. The plantlets were then transplanted to small plastic pots containing only sand or sand and garden soil 1:1 or vermi compost, coir dust and garden soil in the ratio of 2:1:1 treated with $0.1 \%$ Agrason. Data were recorded after 7 days, 15 days and 30 days interval and the acclimatized plantlets showed $84 \%$ survival rate after 30 days of transplantation in the mixture of vermin compost, coir dust and garden soil (Fig. K), whereas only $50 \%$ plantlets survived in garden soil (Table 4 ). 
Table 2. Effect of subculturing on MS with different concentration of BA for multiple shoot regeneration of red variety Gerbera.

\begin{tabular}{|c|c|c|c|c|c|}
\hline $\begin{array}{l}\text { Hormonal } \\
\text { BA(mg/l) }\end{array}$ & supplement & Explants & $\begin{array}{l}\% \text { of } \\
\text { subculturing } \\
\text { clumps }\end{array}$ & $\begin{array}{l}\text { No. of shoots/ explant ( } \\
\bar{X} \pm S E \text { ) }\end{array}$ & $\begin{array}{l}\text { Length of } \quad \begin{array}{l}\text { shoot }(\mathrm{cm}) / \\
\text { explants }(\mathrm{X} \pm \mathrm{SE})\end{array}\end{array}$ \\
\hline \multirow{3}{*}{1.0} & & FB & 74.78 & $08.54 \pm 0.98$ & $2.50 \pm 0.04$ \\
\hline & & FS & 69.57 & $06.48 \pm 1.02$ & $2.80 \pm 0.34$ \\
\hline & & LS & 66.25 & $03.74 \pm 1.32$ & $2.70 \pm 0.06$ \\
\hline \multirow{3}{*}{\multicolumn{2}{|c|}{2.0}} & FB & 96.25 & $22.64 \pm 0.02$ & $4.60 \pm 0.01$ \\
\hline & & FS & 90.86 & $16.15 \pm 0.11$ & $4.10 \pm 0.07$ \\
\hline & & LS & 87.58 & $13.67 \pm 0.23$ & $3.80 \pm 0.20$ \\
\hline \multirow{3}{*}{\multicolumn{2}{|c|}{3.0}} & FB & 78.50 & $16.50 \pm 0.20$ & $3.70 \pm 0.18$ \\
\hline & & FS & 72.23 & $10.25 \pm 0.74$ & $2.90 \pm 0.24$ \\
\hline & & LS & 70.33 & $09.23 \pm 0.85$ & $2.04 \pm 0.78$ \\
\hline \multirow{3}{*}{\multicolumn{2}{|c|}{4.0}} & FB & 70.32 & $11.80 \pm 0.34$ & $2.40 \pm 0.32$ \\
\hline & & FS & 67.44 & $08.75 \pm 0.54$ & $2.60 \pm 0.44$ \\
\hline & & LS & 64.28 & $07.28 \pm 0.87$ & $3.12 \pm 0.52$ \\
\hline \multirow{3}{*}{5.0} & & FB & 60.23 & $07.08 \pm 0.32$ & $1.90 \pm 0.98$ \\
\hline & & FS & 55.25 & 06.550 .34 & $1.34 \pm 0.62$ \\
\hline & & LS & 50.78 & $03.26 \pm 0.56$ & $1.01 \pm 0.88$ \\
\hline
\end{tabular}

FB = Flower bud, FS = Flower stalk, LS = Leaf segment

Table 3. Effect of different concentration PGRs on root induction of red variety.

\begin{tabular}{|c|c|c|c|c|}
\hline $\begin{array}{l}\text { Growth regulator } \\
(\mathrm{mg} / \mathrm{l})\end{array}$ & $\%$ of response & $\begin{array}{l}\text { Mean length of } \\
\text { roots }(\mathrm{cm})\end{array}$ & $\begin{array}{l}\text { No. of roots/micro } \\
\text { shoot }\end{array}$ & Nature of roots \\
\hline $\begin{array}{l}\text { IAA } \\
0.1 \\
0.2 \\
0.3 \\
0.4 \\
0.5\end{array}$ & $\begin{array}{l}15 \\
30 \\
40 \\
25 \\
20\end{array}$ & $\begin{array}{l}1.6 \pm 0.56 \\
1.8 \pm 0.38 \\
2.3 \pm 0.26 \\
2.1 \pm 0.18 \\
1.9 \pm 0.13\end{array}$ & $\begin{array}{l}2.2 \pm 0.53 \\
2.0 \pm 0.22 \\
2.0 \pm 0.01 \\
1.0 \pm 0.11 \\
1.0 \pm 0.11\end{array}$ & Long \& thin \\
\hline $\begin{array}{l}\text { IBA } \\
0.1 \\
0.2 \\
0.3 \\
0.4 \\
0.5\end{array}$ & $\begin{array}{l}47 \\
70 \\
81 \\
71 \\
32\end{array}$ & $\begin{array}{l}3.8 \pm 0.13 \\
4.0 \pm 0.09 \\
4.9 \pm 0.02 \\
4.2 \pm 0.11 \\
3.6 \pm 0.17\end{array}$ & $\begin{array}{l}2.0 \pm 0.33 \\
3.2 \pm 0.50 \\
4.1 \pm 0.11 \\
1.5 \pm 0.70 \\
1.0 \pm 0.70\end{array}$ & Long \& thick \\
\hline $\begin{array}{l}\text { NAA } \\
0.1 \\
0.2 \\
0.3 \\
0.4 \\
0.5\end{array}$ & $\begin{array}{l}\text { Only callus } \\
\text { Only callus } \\
\text { Only callus } \\
\text { Only callus } \\
\text { Only callus }\end{array}$ & $\begin{array}{l}- \\
- \\
- \\
- \\
-\end{array}$ & $\begin{array}{l}- \\
- \\
- \\
- \\
-\end{array}$ & $\begin{array}{l}- \\
- \\
- \\
- \\
-\end{array}$ \\
\hline
\end{tabular}


Table 4. Acclimatization of in vitro regenerated plantlets of Gerbera red variety under ex vitro condition. Data were recorded after 7 days, 15 days and 30 days interval from transplantation date.

\begin{tabular}{|c|c|c|c|c|}
\hline \multirow{2}{*}{ Treatment } & \multirow{2}{*}{$\begin{array}{l}\text { No. of plantlets } \\
\text { transplanted }\end{array}$} & \multicolumn{3}{|c|}{$\%$ of plantlets survived } \\
\hline & & After 7 days & After 15 days & After 30 days \\
\hline Sand & \multirow{3}{*}{150} & 66.6 & 56.6 & 33.60 \\
\hline $\mathrm{VC}+\mathrm{CD}+\mathrm{GS}$ & & 95.0 & 86.0 & 84.60 \\
\hline GS & & 76.6 & 68.6 & 50.00 \\
\hline
\end{tabular}

VC: Vermi compost; CD: Coir dust; GS: Garden soil
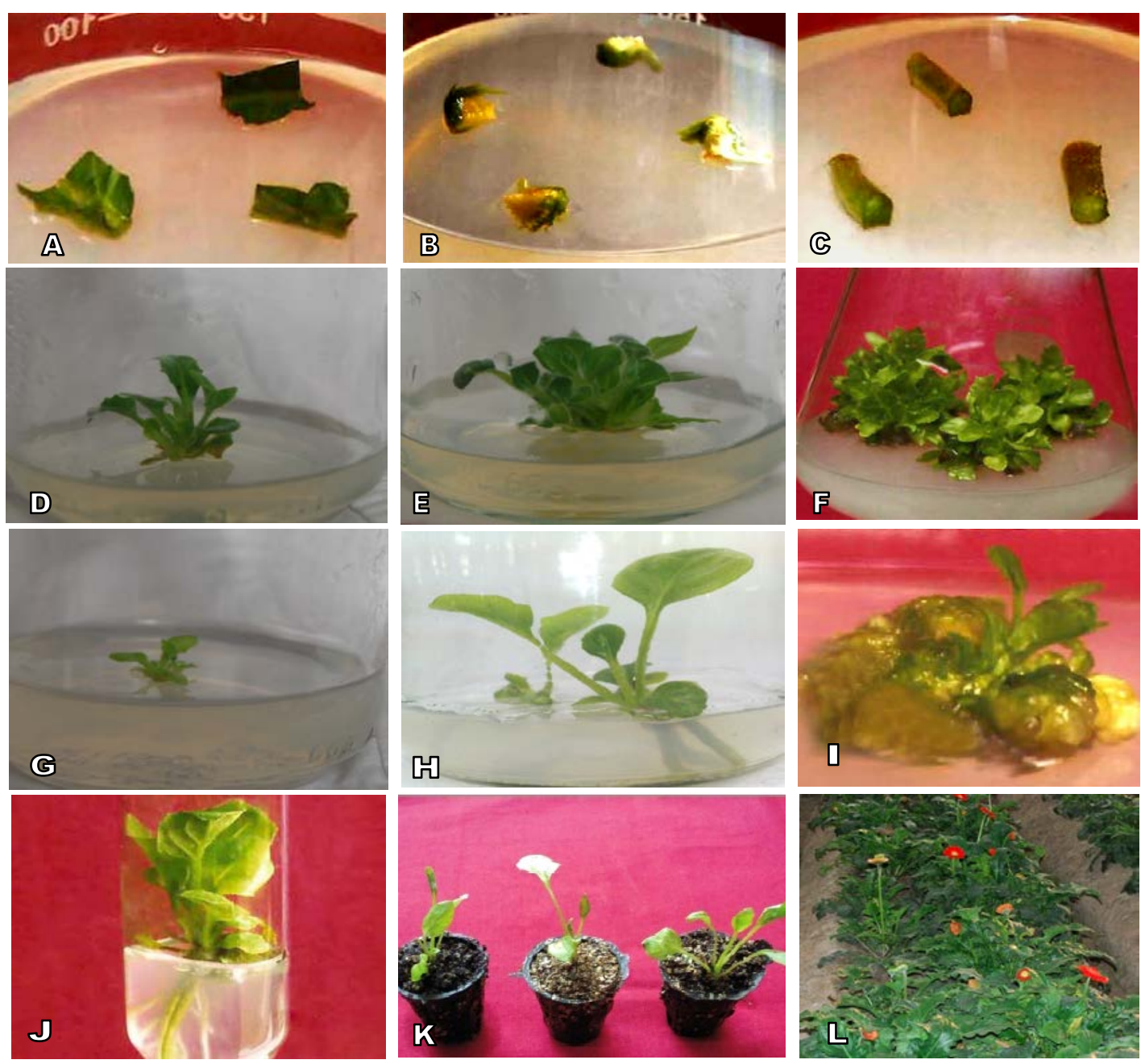
Fig. (A) Leaf segments as explants inoculated in MS+BA+NAA. Fig. (B) Flower bud as explants inoculated in MS+BA+NAA. (C) Flower stalk segments as explants inoculated in MS+BA+NAA. Fig. (D) Shoots were regenerated directly from flower bud explants in MS+BA $5.0 \mathrm{mg} / \mathrm{I}+$ NAA $1.0 \mathrm{mg} / \mathrm{l}$. The highest no of regeneration was recorded with this combination. Fig. (E) Multiplication of shoots after 3 weeks of regeneration in MS+BA $2.0 \mathrm{mg} / \mathrm{l}$. (F) Multiplication of shoots after 4 weeks of regeneration in MS+BA 2.0 mg/l. Fig. (G) Root initiation from regenerated shoots cultured in MS+IBA $0.3 \mathrm{mg} / \mathrm{l}$. Fig. (H) Rooted plantlet after 3 weeks. Fig. (I) Among all hormones used for rooting, callus initiated at the base of explants in MS+NAA. Fig. (J) Well rooted plantlet of red Gerbera suitable for acclimatization in MS+IBA $0.3 \mathrm{mg} / \mathrm{l}$ after 25 days. Fig. (K) Acclimatization of plantlets on pots containing vermin compost: coir dust: garden soil in the ratio of 2:1:1. Fig. (L) Mature plants of Gerbera red variety having flower after 80 days of plantation.

The present study describes an efficient, rapid and reproducible protocol for in vitro propagation of Gerbera red variety with the maximum survival rate and was the first time successful commercial cultivation method generated and being explored among farmers in Bangladesh. This plantlets are already introduced to the farmers' level at Gothkhali, Jessore, a commercial flower cultivating region in Bangladesh (Fig. L). This could also be profitably used for the commercial utilization all over Bangladesh. In the light of global demand, Gerbera could be a major source of foreign exchange as nontraditional export item. Using conventional propagation method, it is really not possible to fulfill the requirements of both local and foreign demands. In this respect, commercial production of Gerbera using in vitro techniques could be acted as a new dimension in Bangladesh economy.

\section{References}

1. Kanwar JK, Kumar S. In vitro propagation of Gerbera- A Review. Hort. Sd., 2008. 35 (1), 35-44.

2. Parthasarathy VA, Nagaraju V. In vitro propagation in Gerbera jamesonii Bolus. Indian Journal of Horticulture. 1999; 56: 8285.

3. Schiva T. Annali deli’ Istituto Sperimentale per Ia Floricoltura. 1975; 6:133-5.

4. Murashige T, Serpa M, Jones JB.,Clonal multiplication of Gerbera through tissue culture. Hort. Sci. 1974; 9: 175-180.

5. Reynoird PC, Chriqui D, Noin M, Brown S, Marie D. Plant propagation from in vitro leaf culture of several Gerbera species. Plant cell, Tissue \& Org. Cult. 1993; 33: 203-210.

6. Palai SK, Pattnaik S, Pattnaik AK, Das P. Efficient plant regeneration through callus culture in Gerbera. Orissa J. Hort 1998; 26: 82-87.

7. Aswath CR, Choudhary ML. Rapid plant regeneration from Gerbera jamesonii. Acta Bot. Croat. 2002; 61(2):125-134.

8. Zhang, W. Research on rapid propagation of Gerbera jamesonii. Fujian Agric. Sci. Technol. 2002; 1: 17-18.

9. Hackett WP, Anderson JM. Aseptic multiplication and maintenance of differentiated Dianthus caryophyllus shoot tissue derived from shoot apices. Hort. Sci. 1967; 90:363-369.

10. Hasbullah NA, Taha RM, Awal A. Growth Optimization and Organogenesis of Gerbera jamesonii Bolus ex Hook f. in vitro. Pak. J. of Bio. Sci. 2008; 11(11): 1449-1454.

11. Shabde M, Murashige T. Hormonal requirements of excised Dianthus caryophyllus L. Shoot apical meristem in vitro. Am. J. Bot. 1977; 64: 433-448.

12. Pillai SK, Hildebrandt AC. Induced differentiation of Germanium plants from undifferentiated in vitro. Am. J. Bot. Soc. 1969; 56: 52-53.

13. Xi M, Shi JS. Tissue culture and rapid propagation of Gerbera jamesonii. Journal Wanjing Forestry University. 2003; 27: 3336.

14. Ben-Jaacov J, Langharis RW. Rapid multiplication of chrysanthemum plants by stem tip proliferation. Hort. Sci. 1972; 7(3): 289-290.

15. Earle ED, Langhans RW. Propagation of chrysanthemum in vitro. I. Multiple plantlets from shoot tips and the establishment of tissue cultures. J. Amer. Soc. fort. Sci. 1974; 99: 128-132.

16. Bush SR, Earle ED, Langhans RW. Plantlets from petal segments, petal epidermis and shoot tips of the periclinal chimera, Chrysanthemum morifolium “Indianapolis”. Amer. J. Bot. 1976; 63: 729-737.

17. Bhattacharya P, Dey S, Das N, Bhattacharya BC. Rapid mass propagation of Chrysanthemum morifilium by callus derived from stem and leaf explants. Plant Cell Reports. 1990; 9:439-442.

18. Shabanpour K, Sharifi A, Bagheri A, Moshtaghi N. Effect of genotypes and culture medium on shoot regeneration and proliferation of Gerbera jamesonii. African Journal of Biotechnology. 2011; 10 (57): 12211-12217.

19. Vardja R, Vardja T. The effect of cytokirlin type and concentration and the number of sub on the multiplication rate of some decorative plants. Proc. Est. Acad. Sd. Biol. Ecol. 2001; 50: 22-32.

20. Chakrabarty D, Datta SK. Micropropagation of Gerbera: lipid peroxidation and antioxidant enzyme activities during acclimatization process. Acta Physiol Plant. 2008; 30: 325-331. 